\title{
Efeitos de indicadores e dias de coleta na digestibilidade dos nutrientes e nas estimativas do valor energético de alimentos para vacas alimentadas com diferentes fontes de proteína ${ }^{1}$
}

\author{
Douglas dos Santos Pina ${ }^{2}$, Sebastião de Campos Valadares Filho ${ }^{3}$, Edenio Detmann ${ }^{3}$, Rilene \\ Ferreira Diniz Valadares ${ }^{4}$, José Maurício de Souza Campos ${ }^{3}$, Kamila Andreatta Kling de \\ Moraes $^{5}$, André Soares de Oliveira ${ }^{2}$, Mônica Lopes Paixão
}

\author{
1 Parte da tese de Mestrado do primeiro autor parcialmente financiada pelo CNPq/FAPEMIG. \\ 2 Doutorando em Zootecnia - UFV. Bolsista do CNPq. \\ ${ }^{3}$ DZO/UFV. Pesquisador do CNPq. \\ ${ }^{4}$ DVT/UFV. Pesquisador do CNPq. \\ 5 Graduação DZO/UFV. Bolsista do PIBIC - CNPq.
}

RESUMO - Foram utilizadas 12 vacas da raça Holandesa, entre puras e mestiças, distribuídas em três quadrados latinos 4 x 4, organizados de acordo com os dias em lactação, com o objetivo de avaliar o efeito de dois períodos de coleta de fezes (dois ou seis dias), em intervalos de 26 horas, e de dois indicadores (fibra em detergente neutro indigestível (FDNi) ou fibra insolúvel em detergente ácido indigestível (FDAi)) na estimativa da excreção de matéria seca fecal (EMSF), do coeficiente de digestibilidade dos nutrientes e dos teores de NDT. Avaliou-se também a eficiência do conjunto de equações somativas propostas pelo NRC (2001) para estimar o valor energético dos alimentos utilizando-se $60 \%$ de silagem de milho com base da MS total das dietas. Os concentrados foram constituídos de diferentes fontes protéicas (FS - farelo de soja; FA38 - farelo de algodão 38\%PB; FA28 - farelo de algodão 28\%PB e FSU - farelo de soja + 5\% de uréia/sulfato de amônia na MS do concentrado). Não foram observados efeitos dos dias de coleta de fezes e dos indicadores sobre as estimativas da EMSF, dos coeficientes de digestibilidade dos nutrientes e dos teores de NDT. As equações propostas pelo NRC (2001) subestimaram os consumos de CNF e EE digestíveis e NDT e superestimaram os de FDN e PB digestíveis. Dois dias de coleta de fezes são suficientes para estimativa da digestibilidade dos nutrientes e, conseqüentemente, do consumo de NDT. A FDNi foi o indicador mais preciso para estimar a excreção de MS fecal. As equações propostas pelo NRC (2001) não foram adequadas para estimar o valor energético dos alimentos em condições tropicais.

Palavras-chave: consumo, energia, farelo de algodão, farelo de soja, leite, uréia

\section{Comparison of internal markers and extent of total fecal collection to estimate nutrient digestibility and energy value of feeds on dairy cows fed different protein sources}

\footnotetext{
ABSTRACT - Twelve lactating dairy cows (Holstein and crossbred Holstein x Zebu) were blocked by days in milk and randomly assigned to three replicate 4 x 4 Latin squares to compare two schedules of total fecal collection (two versus six days) and the reliability of two internal markers [indigestible neutral detergent fiber (INDF) or indigestible acid detergent fiber (IADF)] to estimate fecal DM excretion (FDME), apparent total tract digestibility of nutrients, and the total digestible nutrients (TDN) content of the diets. The summative equations from the NRC (2001) model were also used to estimate the energy value of feeds. A diet containing $60 \%$ of corn silage (DM basis) plus one of the following proteins sources was fed to animals: soybean meal (SM), 38\% CP cottonseed meal (CM38), 28\% CP cottonseed meal (CM28), or SM plus 5\% of urea/ ammonium sulfate in the concentrate DM (SMU). Fecal collection schedule and markers had no effect on the estimates of FDME, nutrient digestibility, and dietary TDN. The summative equations from the NRC (2001) overestimated the intake of digestible CP and NDF and underestimated that of digestible NFC, EE, and TDN. It was concluded that INDF was the most precise marker and two days of total fecal collection was enough to estimate FDME, nutrient digestibility and dietary TDN. The NRC (2001) summative equations did not reliably predict the energy value of tropical feeds.
}

Key Words: cottonseed meal, energy, equations, intake, soybean meal, urea 


\section{Introdução}

A caracterização do valor nutritivo dos alimentos, que envolve consumo, digestibilidade e eficiência de utilização do alimento (Freitas et al., 2002), tem grande importância para os ruminantes, pois possibilita inferir sobre sua utilização por esses animais.

Após o conhecimento da composição química, a obtenção de estimativas dos valores de digestibilidade é reconhecidamente essencial para determinar o valor nutritivo dos alimentos (Valadares Filho et al., 2000). Segundo Pereira (2005), a digestibilidade dos nutrientes é um dos principais fatores na determinação da energia dos alimentos destinada à produção de leite, ou seja, energia líquida de lactação $\left(\mathrm{EL}_{\mathrm{L}}\right)$, energia metabolizável (EM), energia digestível (ED) ou nutrientes digestíveis totais (NDT). Entretanto, existe uma complexa relação entre proteína dietética e energia e a quantidade de proteína que será utilizada pelo animal (Broderick, 2003).

O controle rigoroso do consumo e/ou da produção fecal pode, em algumas situações, não ser possível, como, por exemplo, na ausência de instalações adequadas, em animais em pastejo ou quando o parâmetro a ser estudado não pode ser mensurado diretamente, como a digestibillidade ruminal ou os estudos sobre o trânsito da digesta (Berchielli et al., 2006). Dessa forma, em vários métodos são utilizados indicadores para estimar a produção fecal e, conseqüentemente, a digestibilidade dos nutrientes. Essas avaliações se baseiam na razão entre a quantidade do indicador administrada ao animal e sua concentração nas fezes (Aroeira, 1997).

Segundo Berchielli et al. (2000), os indicadores podem ou não estar presentes naturalmente na dieta e subdividem-se em internos e externos. Entre os indicadores internos, têm-se estudado alguns componentes da fração fibrosa dos alimentos, como a FDNi e a FDAi.

De forma alternativa aos métodos biológicos, existe uma perspectiva de utilização da composição química dos alimentos como método de predição da digestibilidade em ruminantes, como sugerido por alguns autores (Weiss et al., 1992; Van Soest, 1994). Diante dessa perspectiva, o NRC (2001) sugeriu a adoção de um método com esse embasamento para a estimação do teor de NDT dos alimentos a partir de um conjunto de equações somativas nas quais se considera cada uma das frações dos alimentos (PB, EE, CNF e FDN) utilizadas para determinar o teor de NDT. Todavia, embora seja um sistema amplamente difundido e, teoricamente, satisfatório para o uso em condições temperadas, esse conjunto de equações não tem apresentado eficiência de predição satisfatória quando aplicado a alimentos obtidos em condições tropicais, tornando as estimativas substancialmente desviadas dos valores observados in vivo (Costa, 2002; Rocha Jr. et al., 2003; Silva, 2004; Oliveira, 2005).

Neste contexto, este trabalho foi conduzido com o objetivo de avaliar o efeito de dois períodos de coleta de fezes (dois ou seis dias) em intervalos de 26 horas, e de dois indicadores (FDNi ou FDAi) na estimativa da excreção de matéria seca fecal (EMSF), do coeficiente de digestibilidade dos nutrientes e dos teores de NDT. Avaliou-se ainda a viabilidade de utilização do sistema de equações proposto pelo NRC (2001) para estimar o consumo de nutrientes digestíveis (PB, EE, FDN, CNF e NDT) por meio da composição química dos alimentos em condições tropicais.

\section{Material e Métodos}

O experimento foi realizado na Unidade de Ensino, Pesquisa e Extensão em Gado de Leite (UEPE-GL) do Departamento de Zootecnia da Universidade Federal de Viçosa (UFV), Viçosa-MG. Foram utilizados 12 animais da raça Holandesa (550 kg de PV e produção de leite de aproximadamente $25 \mathrm{~kg} /$ dia) distribuídos em três quadrados latinos 4 x 4, organizados de acordo com os dias em lactação.

A proporção dos ingredientes na mistura de concentrados, a composição dos concentrados e da silagem de milho e a composição das dietas experimentais podem ser observadas nas Tabelas 1,2 e 3 , respectivamente.

Tabela 1 - Proporção dos ingredientes no concentrado, expressa na MS

Table 1 - Ingredient composition of the concentrate, \% of DM

\begin{tabular}{|c|c|c|c|c|}
\hline \multirow[t]{2}{*}{$\begin{array}{l}\text { Ingrediente } \\
\text { Ingredient }\end{array}$} & \multicolumn{4}{|c|}{$\begin{array}{l}\text { Concentrado } \\
\text { Concentrate }\end{array}$} \\
\hline & $\begin{array}{l}\text { FS } \\
S M\end{array}$ & $\begin{array}{l}\text { FA38 } \\
\text { CM38 }\end{array}$ & $\begin{array}{l}\text { FA28 } \\
\text { CM28 }\end{array}$ & $\begin{array}{l}\text { FSU } \\
S M U\end{array}$ \\
\hline Fubá de milho & 43,67 & 29,81 & 15,42 & 62,01 \\
\hline $\begin{array}{l}\text { Ground corn } \\
\text { Farelo de soja } \\
\text { Soybean meal }\end{array}$ & 41,61 & - & 14,39 & 19,77 \\
\hline $\begin{array}{l}\text { Farelo de trigo } \\
\text { Wheat meal }\end{array}$ & 10,00 & 10,00 & 10,00 & 10,00 \\
\hline $\begin{array}{l}\text { Farelo de algodão } 38 \\
\text { Cottonseed meal } 38\end{array}$ & - & 55,47 & - & - \\
\hline $\begin{array}{l}\text { Farelo de algodão } 28 \\
\text { Cottonseed meal } 28\end{array}$ & - & - & 55,47 & - \\
\hline $\begin{array}{l}\text { Uréia/SA } \\
\text { Urea/AS }\end{array}$ & 1,50 & 1,50 & 1,50 & 5,00 \\
\hline $\begin{array}{l}\text { Mistura mineral } \\
\text { Mineral mix }\end{array}$ & 3,22 & 3,22 & 3,22 & 3,22 \\
\hline
\end{tabular}

$\mathrm{FS}=$ farelo de soja $\mathrm{FA3} 8$ = farelo de algodão com $38 \%$ de PB; FA28 = farelo de algodão com $28 \%$ de PB e FSU = FS + uréia.

$S M=$ soybean meal; $C M 38=38 \% C P$ cottonseed meal; $C M 28=28 \% C P$ cottonseed meal $S M U=S M+$ urea . 
Ao término do experimento, as amostras de alimentos, fezes e sobras foram descongeladas, pré-secas em estufa de ventilação forçada a $60 \pm 5^{\circ} \mathrm{C}$ (72 a 96 horas) e, posteriormente, trituradas em moinho tipo Willey com peneira de porosidade $1 \mathrm{~mm}$. As análises para determinação dos teores de MS, cinzas, EE, FDN, FDA e compostos nitrogenados totais foram conduzidas segundo método descrito por Silva \& Queiroz (2002). A porcentagem de CNF nos concentrados foi obtida segundo Hall \& Akinyode (2000); CNF $=100-$ $[(\% \mathrm{~PB}-\% \mathrm{PBU}+\% \mathrm{U})+\% \mathrm{FDN}+\% \mathrm{EE}+\%$ Cinzas $], \mathrm{em}$ que PBU é a porcentagem de $\mathrm{PB}$ proveniente da uréia e $\mathrm{U}$, a porcentagem de uréia no concentrado. Os NDT foram estimados conforme método descrito por Weiss et al. (1992): $\mathrm{NDT}=\mathrm{PBd}+\mathrm{FDNd}+\mathrm{CNFd}+2,25 \mathrm{x} \mathrm{EEd}$, em que PBd, FDNd, CNFd e EEd representam o total dos respectivos nutrientes digestíveis.

Foram comparados os consumos de PBd, EEd, FDNd, CNFd e NDT observados e estimados pelas equações propostas pelo NRC (2001) utilizando-se a frações metabólicas fecais ajustadas de 2,625; 1,361 e 3,014 para PB, EE e $\mathrm{CNF}$, respectivamente, para transformar a digestibilidade verdadeira em digestibilidade aparente, de modo que a fração metabólica do NDT foi a soma das anteriores, considerando o valor 7,00, segundo Weiss et al. (1992).

A avaliação foi realizada por meio do ajuste de modelo de regressão linear simples (Regressão 1.: Yi $=\beta_{0}+\beta_{0} \mathrm{Xi}+$ $\mathrm{e}_{\mathrm{i}}$ ) dos valores preditos sobre os observados, conforme descrito por Rocha Jr. et al. (2003). As estimativas dos parâmetros de regressão foram testadas sobre as seguintes hipóteses (1 e 2):
(1) $\mathrm{H}_{0}: \beta_{0}=0$
(2) $\mathrm{H}_{0}: \beta_{1}=1$
Ha : $\beta_{0} \neq 0$
Ha : $\beta_{1} \neq 1$

No caso de não-rejeição de ambas as hipóteses de nulidade, concluiu-se que os valores preditos e observados foram similares. Em situação contrária, nova equação de regressão foi traçada, suprimindo-se o parâmetro relativo ao intercepto (Regressão 2), de acordo com o seguinte modelo: $\mathrm{Yi}=\beta_{0} \mathrm{Xi}+\mathrm{e}_{\mathrm{i}}$. No caso de rejeição da hipótese de nulidade 1 e aceitação da hipótese de nulidade 2, concluiu-se que houve correspondência, com presença de vício constante, que corresponde à estimativa do intercepto. Quando houve aceitação da primeira e rejeição da segunda hipótese de nulidade, verificou-se a presença de vício global de estimação (BGE). Havendo rejeição das duas hipóteses, certificou-se a presença de dois vícios e considerou-se apenas o BGE.

As análises estatísticas foram realizadas segundo de lineamento em quadrado latino, aplicando-se o teste $\mathrm{F}$ a $5 \%$ de probabilidade para todas as variáveis analisadas correspondentes aos dias de coleta de fezes (dois ou seis) e aos indicadores (FDNi ou FDAi) utilizando-se ainda um esquema de parcelas sub-subdivididas, em que as parcelas foram compostas pelas dietas, as subparcelas pelos dias de coleta de fezes e as sub-subparcelas pelos indicadores.

Tabela 4 - Médias diárias para as excreções de MS fecal (EMSF) e os coeficientes de digestibilidade de MS (CDMS), MO (CDMO), PB (CDPB), EE (CDEE), FDN (CDFDN) e CNF (CDCNF) e os teores de NDT, estimadas utilizando-se a FDNi ou a FDAi como indicadores internos

Table 4 - Average daily fecal DM excretion (FDME) and digestibility coefficients of DM (DCDM), OM (DCOM), CP (DCCP), EE (DCEE), NDF (DCNDF), NFC (DCNFC) and TDN content estimated using the indigestible neutral detergent fiber (INDF) or indigestible acid detergent fiber (IADF) as internal markers

\begin{tabular}{|c|c|c|c|c|c|}
\hline \multirow[t]{3}{*}{$\begin{array}{l}\text { Variável } \\
\text { Item }\end{array}$} & \multicolumn{2}{|c|}{$\begin{array}{l}\text { Média } \\
\text { Mean }\end{array}$} & \multirow[t]{3}{*}{$\mathrm{CV}(\%)$} & \multicolumn{2}{|c|}{$\begin{array}{l}\text { Erro-padrão } \\
\text { Standard error }\end{array}$} \\
\hline & FDNi & FDAi & & FDNi & FDAi \\
\hline & $I N D F$ & $I A D F$ & & $I N D F$ & $I A D F$ \\
\hline $\operatorname{EMSF}(F D M E)(\mathrm{kg} / \mathrm{d})$ & $6,85 b$ & $7,07 \mathrm{a}$ & 6,33 & 0,107 & 0,125 \\
\hline CDMS $(D C D M)(\%)$ & $64,22 \mathrm{a}$ & $63,13 b$ & 3,54 & 0,465 & 0,548 \\
\hline $\operatorname{CDMO}(D C O M)(\%)$ & $65,60 \mathrm{a}$ & $64,56 b$ & 3,31 & 0,469 & 0,550 \\
\hline $\mathrm{CDPB}(D C C P)(\%)$ & $69,78 \mathrm{a}$ & $68,84 b$ & 3,05 & 0,455 & 0,535 \\
\hline $\operatorname{CDEE}(D C E E)(\%)$ & $84,51 \mathrm{a}$ & $84,05 \mathrm{a}$ & 2,64 & 0,532 & 0,565 \\
\hline CDFDN $(D C N D F)(\%)$ & $46,85 \mathrm{a}$ & $45,28 b$ & 7,29 & 0,602 & 0,704 \\
\hline $\operatorname{CDCNF}(D C N F C)(\%)$ & $90,22 \mathrm{a}$ & $89,91 b$ & 0,85 & 0,277 & 0,297 \\
\hline NDT $(T D N)(\% \mathrm{MS})$ & $68,36 \mathrm{a}$ & $67,36 b$ & 3,20 & 0,538 & 0,606 \\
\hline
\end{tabular}

${ }_{1}^{1}$ Médias na mesma linha seguidas por letras distintas diferem $(P<0,05)$ pelo teste $F$.

${ }^{1}$ Means in the same row followed by different letters differ $(P<0.05)$ by $F$ test. 


\section{Resultados e Discussão}

As médias diárias para as excreções de matéria seca fecal (EMSF) e os coeficientes de digestibilidade de MS, EE, $\mathrm{PB}, \mathrm{FDN}, \mathrm{CNF}$ e os teores de NDT estimados utilizando-se FDNi ou FDAi como indicador interno em dois ou seis dias de coleta de fezes podem ser observadas na Tabelas 4 e 5 , respectivamente. Não houve interação $(\mathrm{P}>0,05)$ entre os dias de coleta e indicadores.

Houve diferença significativa $(\mathrm{P}<0,05)$ entre os dois indicadores para estimar a EMSF e, conseqüentemente, os coeficientes de digestibilidade da MS, PB, FDN e CNF, mas não para o coeficiente de digestibilidade do EE. O uso da FDAi, em relação ao da FDNi, resultou em maior excreção de matéria seca fecal, o que refletiu em menores estimativas dos coeficientes de digestibilidade de MS, PB, FDN e CNF $(\mathrm{P}<0,05)$. Apesar da diferença entre os indicadores, essa diferença pode ser explicada pelo grande número de graus de liberdade (84) associado ao resíduo da sub-subparcela e pelos baixos coeficientes de variação, que indicam boa precisão e alta confiabilidade dos dados.

Essas pequenas diferenças entre as estimativas de EMSF e os coeficientes de digestibilidade dos nutrientes obtidas com o uso dos dois indicadores podem não ser biologicamente significantes, o que estaria de acordo com os relatos de Berchielli et al. (1998), que não encontraram diferença $(\mathrm{P}>0,05)$ entre o FDNi e o FDAi ao estimarem a digestibilidade da MS e MO. Ambos os indicadores foram confiáveis para estimar a EMSF. Contudo, o mais preciso nesse experimento foi a FDNi, tendo em vista o menor erropadrão associado às suas estimativas (Tabela 4).

Como demonstrado na Tabela 5, os resultados não diferiram $(\mathrm{P}>0,05)$ entre os dias de coleta, para todas as variáveis analisadas, sugerindo que dois dias (às 8 e às 16h) de coleta de fezes são suficientes para estimar a excreção de matéria seca fecal, a digestibilidade e, conseqüentemente, os teores de nutrientes digestíveis (NDT). Ítavo et al. (2002) também não encontraram diferença entre dois ou seis dias de coleta de fezes quando compararam o uso de óxido de cromo ao de FDAi para estimar a digestibilidade aparente total da MS.

A utilização de dois dias de coleta de fezes possibilita a obtenção dos coeficientes de digestibilidade de modo mais prático e rápido em experimentos com animais em regime de confinamento, pois diminuiu os custos com mãode-obra, o tempo e o stress causado pelo manejo aos animais. Espera-se que esses resultados possam também ser aplicados em condições de pastejo.

Essas pressuposições foram reforçadas pelos resultados obtidos por Detmann et al. (2005), que observaram alta estabilidade para a excreção nictemeral de indicadores
Tabela 5 - Médias diárias para as excreções de matéria seca fecal (EMSF), os coeficientes de digestibilidade de MS (CDMS), MO (CDMO), PB (CDPB), EE (CDEE), FDN (CDFDN) e CNF (CDCNF) e os teores de NDT, estimadas com dois ou seis dias de coleta de fezes

Table 5 - Average daily fecal dry matter excretion (FDME) and digestibility coefficients of DM (DCDM), OM (DCOM), CP (DCCP), EE (DCEE), NDF (DCNDF), NFC (DCNFC) and TDN content determined with two or six days of total fecal collection

\begin{tabular}{|c|c|c|c|}
\hline \multirow[t]{2}{*}{ Item } & \multicolumn{2}{|c|}{$\begin{array}{l}\text { Dias de amostragem } \\
\text { Sampling days }\end{array}$} & \multirow[t]{2}{*}{$\mathrm{CV}(\%)$} \\
\hline & 2 dias (days) & 6 dias (days) & \\
\hline $\operatorname{EMSF}(F D M E)(\mathrm{kg} / \mathrm{dia})$ & $6,84 a$ & $6,87 \mathrm{a}$ & 5,50 \\
\hline CDMS $(D C D M)(\%)$ & $64,30 \mathrm{a}$ & $64,12 \mathrm{a}$ & 3,01 \\
\hline CDMO (DCOM $)(\%)$ & $65,70 \mathrm{a}$ & $65,51 \mathrm{a}$ & 2,73 \\
\hline $\mathrm{CDPB}(D C C P)(\%)$ & $69,91 \mathrm{a}$ & $69,64 \mathrm{a}$ & 4,04 \\
\hline $\operatorname{CDEE}(D C E E)(\%)$ & $84,41 \mathrm{a}$ & $84,59 a$ & 2,37 \\
\hline CDFDN $(D C N D F)(\%)$ & $46,85 \mathrm{a}$ & $46,85 \mathrm{a}$ & 5,98 \\
\hline CDCNF $(D C N F C)(\%)$ & $90,37 \mathrm{a}$ & $90,07 \mathrm{a}$ & 2,14 \\
\hline NDT $(T D N)(\% \mathrm{MS})$ & $68,45 \mathrm{a}$ & $68,28 \mathrm{a}$ & 2,53 \\
\hline
\end{tabular}

${ }_{1}^{1}$ Médias na mesma linha seguidas por letras distintas diferem $(\mathrm{P}<0,05)$ pelo teste $\mathrm{F}$.

${ }^{1}$ Means in the same row followed by different letters differ $(P<0.05)$ by $F$ test.

in ternos (MSi, FDNi e FDAi), o que permite concluir que a alta estabilidade desses indicadores pode possibilitar simplificações nos procedimentos de amostragem fecal sem que o corram comprometimentos sobre a exatidão das estimativas de produção fecal.

Como descrito na Tabela 6, os valores para os interceptos foram diferentes de zero $(\mathrm{P}<0,01)$ para os consumos de CFDND, CEED, CPBD e CNDT e semelhantes a zero $(\mathrm{P}>0,64)$ para $C C N F D$, enquanto os coeficientes de inclinação diferentes de $1(\mathrm{P}<0,01)$ foram observados para CFDND, CCNFD, CPBD e CNDT, sendo que este não diferiu $(\mathrm{P}>0,18)$ para CEED. Considerando o resultado da análise para o consumo de EEd, no qual a hipótese de nulidade para o intercepto foi rejeitada $(\mathrm{P}<0,01)$ e a de nulidade para o coeficiente de inclinação aceita $(P>0,18)$, nota-se que existe uma correspondência na variação, no entanto, com presença de vício constante correspondendo à estimativa do intercepto $(+0,6854)$.

$\mathrm{O}$ resultado para consumo de $\mathrm{CNFd}$, no entanto, em que a hipótese de nulidade para o intercepto foi aceita $(\mathrm{P}>0,64)$ e a de nulidade para o coeficiente de inclinação foi rejeitada $(\mathrm{P}<0,01)$, implica na existência de vício global de estimação (BGE). Os resultados para os consumos de FDNd, PBd e NDTd, nos quais ambas as hipóteses de nulidade foram rejeitadas $(\mathrm{P}<0,01)$, indicam a presença de vícios em suas estimações.

Essas observações podem ser visualizadas nas Figuras 1, 2, 3, 4 e 5, em que são representados os consumos de nutrientes digestíveis (PBd, EEd, FDNd e CNFd) e NDT, respectivamente. Também é possível observar que as equações adotadas pelo NRC (2001) subestimaram os consumos de CNFd e EEd e NDT e superestimaram os de FDNd e PBd. 
Tabela 6 - Consumos médios de nutrientes digestíveis (PBd, EEd, FDNd e CNFd, kg/dia) e teores de NDT (kg/dia) para os valores observados e estimados pelas equações utilizadas no NRC (2001), com suas equações de regressão e de correlação linear

Table 6 - Average intake of digestible crude protein (IDCP, $\mathrm{kg} /$ day), digestible ether extract (IDEE, $\mathrm{kg} /$ day), digestible neutral detergent fiber (IDNDF, $\mathrm{kg} /$ day), digestible nonfiber carbohydrate (IDNFC, $\mathrm{kg} /$ day) and total digestible nutrients (ITDN, $\mathrm{kg} /$ day) for observed and estimated values using the NRC (2001), regression equations, and linear correlation

\begin{tabular}{|c|c|c|c|c|c|c|c|c|c|}
\hline \multirow[t]{2}{*}{ Item } & \multicolumn{2}{|c|}{$\begin{array}{l}\text { Valor médio } \\
\text { Average value }\end{array}$} & \multicolumn{4}{|c|}{$\begin{array}{c}\text { Equação de regressão } \\
\text { Regression equation }\end{array}$} & \multirow[t]{2}{*}{$s_{x y}$} & \multicolumn{2}{|c|}{$\begin{array}{l}\text { Correlação linear } \\
\text { Linear correlation }\end{array}$} \\
\hline & $\begin{array}{c}\text { Observado } \\
\text { Observed }\end{array}$ & $\begin{array}{l}\text { Estimado } \\
\text { Estimated }\end{array}$ & $\begin{array}{l}\text { Intercepto } \\
\text { Intercept }\end{array}$ & $\begin{array}{l}\text { Valor } \mathrm{P}^{2} \\
P \text { value }\end{array}$ & $\begin{array}{c}\text { Coeficiente } \\
\text { Coefficient }\end{array}$ & $\begin{array}{l}\text { Valor } \mathrm{P}^{3} \\
P \text { value }\end{array}$ & & $\begin{array}{c}\text { Estimativa } \\
\text { Estimate }\end{array}$ & $\begin{array}{l}\text { Valor } \mathrm{P}^{4} \\
P \text { value }\end{array}$ \\
\hline CPBD $(I D C P)$ & 2,158 & 2,342 & 1,2020 & 0,0001 & 0,5228 & 0,0008 & 0,1730 & 0,5177 & 0,0002 \\
\hline CEED (IDEE) & 0,499 & 0,293 & $-0,3436$ & 0,0017 & 1,2771 & 0,1824 & 0,0730 & 0,6854 & $<0,0001$ \\
\hline CFDND (IDNDF) & 3,965 & 5,276 & 2,7820 & $<0,0001$ & 0,6291 & $<0,0001$ & 0,3490 & 0,7754 & $<0,0001$ \\
\hline
\end{tabular}

${ }^{1}$ Valores observados considerados como variável independente.

${ }^{2} \mathrm{H}_{0}: \beta_{0}=0 ; \mathrm{Ha}: \beta_{0} \neq 0,{ }^{3} \mathrm{H}_{1}: \beta 0=1 ; \mathrm{Ha}: \beta_{1} \neq 1,{ }^{4} \mathrm{H}_{0}: \rho_{0}=0 ; \mathrm{Ha}: \rho_{0} \neq 0$

1 Observed values were considered as the independent variable.

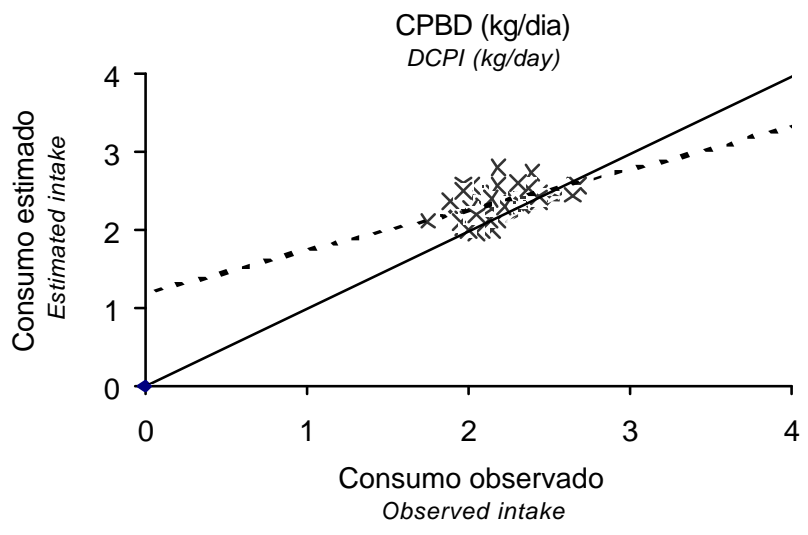

Figura 1 - Comportamento descritivo para a relação entre consumo de proteína bruta digestível (CPBD) observado e estimado pelo sistema de equações do NRC (2001). A linha tracejada corresponde à reta de quadrados mínimos.

Figure 1 - Relationship between observed and estimated (NRC, 2001) digestible crude protein intake (DCPI). The dashed line corresponds to the least square straight line.

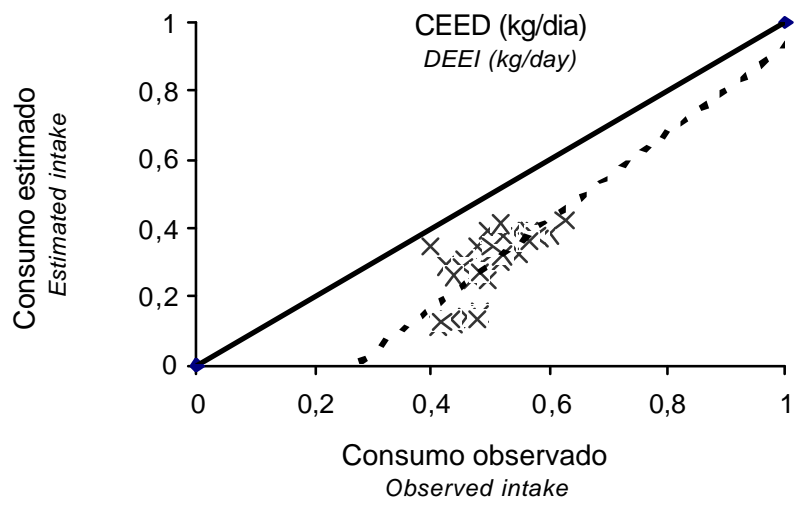

Figura 2 - Comportamento descritivo para a relação entre consumo de extrato etéreo digestível (CEED) observado e estimado pelo sistema de equações do NRC (2001). A linha tracejada corresponde à reta de quadrados mínimos.

Figure 2 - Relationship between observed and estimated (NRC, 2001) digestible ether extract intake (DEEI). The dashed line corresponds to the least square straight line. 


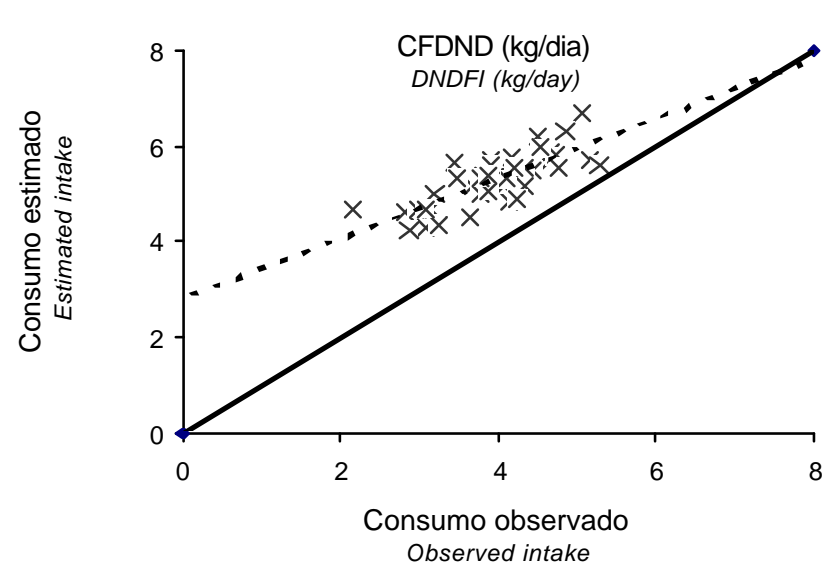

Figura 3 - Comportamento descritivo para a relação entre consumo de fibra em detergente neutro digestível (CFDNd) observado e estimado pelo sistema de equações do NRC (2001). A linha tracejada corresponde à reta de quadrados mínimos.

Figure 3 - Relationship between observed and estimated (NRC, 2001) digestible neutral detergent fiber intake (IDNDF). The dashed line corresponds to the least square straight line.

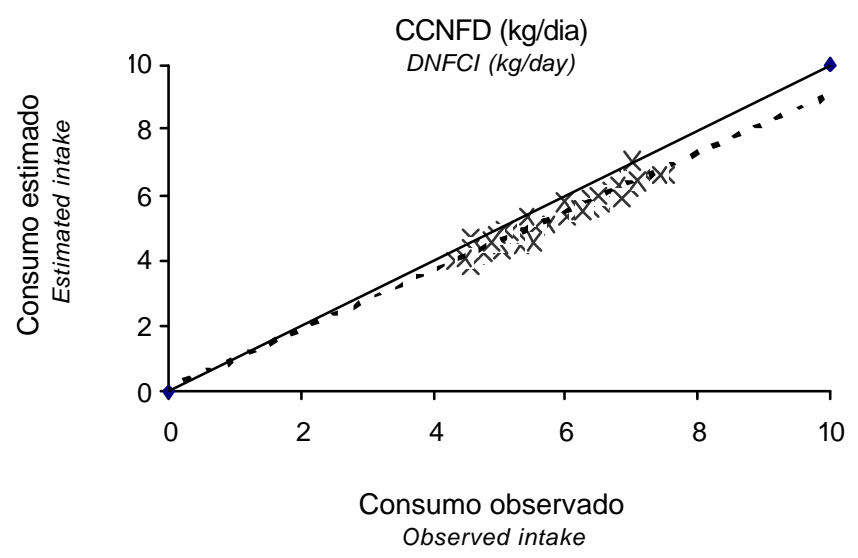

Figura 4 - Comportamento descritivo para a relação entre consumo de carboidratos não-fibrosos digestível (CCNFD) observado e estimado pelo sistema de equações do NRC (2001). A linha tracejada corresponde à reta de quadrados mínimos.

Figure 4 - Relationship between observed and estimated (NRC, 2001) digestible nonfiber carbohydrates intake (DNFCI). The dashed line corresponds to the least square straight line.

\section{Conclusões}

Dois dias de coleta de fezes são suficientes para estimar a digestibilidade dos nutrientes e, conseqüentemente, o consumo de nutrientes digestíveis totais. A FDNi constitui um indicador preciso para estimativa da excreção de matéria seca fecal.

As equações adotadas pelo NRC (2001) mostraram-se inadequadas para estimar os valores energéticos dos alimentos em condições tropicais.

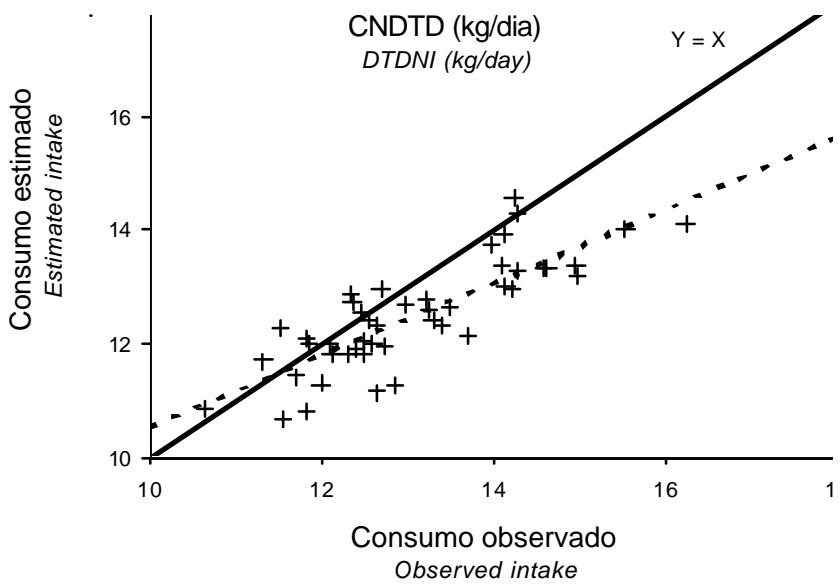

Figura 5 - Comportamento descritivo para a relação entre consumo de nutrientes digestíveis totais (CNDT) observado e estimado pelo sistema de equações do NRC (2001). A linha tracejada corresponde à reta de quadrados mínimos.

Figure 5 - Relationship between observed and estimated (NRC, 2001) total digestible nutrient intake (ITDN). The dashed line corresponds to the least square straight line.

\section{Literatura Citada}

AROEIRA, L.J.M. Estimativas de consumo de gramíneas tropicais. In: SIMPÓSIO INTERNACIONAL DE DIGESTIBILIDADE EM RUMinantes, 1997, Lavras. Anais... Lavras: Universidade Federal de Lavras, 1997. p.127-163.

BERCHIELLI, T.T.; RODRIGUEZ, N.M.; OSÓRIO NETO, E. et al. Comparação de marcadores de fase sólida para medir fluxo de matéria seca e matéria orgânica no duodeno. Arquivo Brasileiro de Medicina Veterinária e Zootecnia, v.50, n.2, p.147-152, 1998.

BERCHIELLI, T.T.; ANDRADE, P.; FURLAN, C.L. Avaliação de indicadores internos em ensaios de digestibilidade. Revista Brasileira de Zootecnia, v.29, n.3, p.830-833, 2000.

BERCHIELLI, T.T.; GARCIA, A.V.; OLIVEIRA, S.G. Principais técnicas de avaliação aplicadas em estudos de nutrição. In: BERCHIELLI, T.T.; PIREZ, A.V.; OLIVEIRA, S.G. (Eds.) Nutrição de ruminantes. Jaboticabal: FUNEP, 2006. 583p.

BRODERICK, G.A. Effects of varying dietary protein and energy levels on the production of lactating dairy cows. Journal of Dairy Science, v.86, p.1370-1381, 2003.

COCHRAN, R.C.; ADANS, D.C.; WALLACE, J.D. et al. Predicting digestibility of different diets with internal markers: evaluation of four potential markers. Journal of Dairy Science, v.63, p.1476-1483, 1986.

COSTA, M.A.L. Desempenho de novilhos zebuínos e validação das equações do NRC (2001) para predizer o valor energético dos alimentos em condições brasileiras. Viçosa, MG: Universidade Federal de Viçosa, 2002. 80p. Dissertação (Mestrado em Zootecnia) - Universidade Federal de Viçosa, 2002.

DETMANN, E.; BARRROS, E.E.L.; FONTES, C.A.A. et al. Avaliação do perfil nictemeral de excreção de indicadores internos em ensaios de digestão com bovinos. In: REUNIÃO ANUAL DA SOCIEDADE BRASILEIRA DE ZOOTECNIA, 42., 2005, Goiânia. Anais... Goiânia: Sociedade Brasileira de Zootecnia, 2005. (CD-ROM). 
FREITAS, D.; BERCHIELLI, T.T.; SILVEIRA, R.N. Produção fecal e fluxo duodenal de matéria seca e matéria orgânica estimados por meio de indicadores. Revista Brasileira de Zootecnia, v.31, n.3, p.1521-1530, 2002 (supl.).

HALL, M.B.; AKINYODE, A. Cottonseed hulls: working with a novel fiber source. In: ANNUAL FLORIDA RUMINANT NUTRITION SYMPOSIUM, 11., 2000, Gainesville.Proceedings... Gainesville: University of Florida, 2000. p.179-186.

ÍTAVO, L.C.V.; VALADARES FILHO, S.C.; SILVA, F.F. et al. Comparação de indicadores e metodologia de coleta para estimativas de produção fecal e fluxo de digesta em bovinos. Revista Brasileira de Zootecnia, v.31, n.4, p.1833-1839, 2002.

NATIONAL RESEARCH COUNCIL - NRC. Nutrient requirements of dairy cattle. 7.ed. Whashington, D.C.: National Academic Press, 2001. 381p.

OLIVEIRA, A.S. Casca de café ou casca de soja em substituição ao milho em dietas à base de cana-de-açúcar para vacas leiteiras. Viçosa, MG: Universidade Federal de Viçosa, 2005. 90p. Dissertação (Mestrado em Zootecnia) - Universidade Federal de Viçosa, 2005.

PEREIRA, M.L.A.; VALADARES FILHO, S.C.; VALADARES, R.F.D. et al. Consumo, digestibilidade aparente total, produção e composição do leite em vacas no terço inicial da lactação alimentadas com níveis crescentes de proteína bruta no concentrado. Revista Brasileira de Zootecnia, v.34, n.3, p.1029-1039, 2005.
ROCHA JR., V.R.; VALADARES FILHO, S.C.; BORGES, A.M. et al. Estimativa do valor energético dos alimentos e validação das equações propostas pelo NRC (2001). Revista Brasileira de Zootecnia, v.32, n.2, p.480-490, 2003.

SILVA, J.D.; QUEIROZ, A.C. Análise de alimentos (métodos químicos e biológicos). 3.ed. Viçosa, MG: Editora UFV, 2002. $235 \mathrm{p}$.

SILVA, P.A. Valor energético do capim-elefante em diferentes idades de rebrota e estimativa da digestibilidade in vivo da fibra em detergente neutro. Viçosa, MG: Universidade Federal de Viçosa, 2004. 72p. Dissertação (Mestrado em Zootecnia) - Universidade Federal de Viçosa, 2004.

VALADARES FILHO, S.C.; BRODERICK, G.A.; VALADARES, R.F.D. et al. Effect of replacing alfalfa silage with high moisture corn on nutrient utilization and milk production. Journal of Dairy Science, v.83, p.106-114, 2000.

Van SOEST, P.J. Nutritional ecology of the ruminant. 2.ed. London: Comstock Publishing Associates, 1994. 476p.

WEISS, W.P.; CONRAD, H.R.; St. PIERRE, N.R. A theoreticallybased model for predicting total digestible nutrient values of forages and concentrates. Animal Feed Science and Technology, v.39, p.95-110, 1992. 